\title{
Evaluation of risk and safety in building structures under construction
}

\author{
Shahram Jkhsi \\ Faculty of Civil and Environmental Engineering, Near East University, Nicosia, Mersin10, Turkey
}

\section{A R T I C LEINFO}

\section{ARTICLE HISTORY:}

Received: 22 April 2020

Revised: 04 May 2020

Accepted: 06 May 2020

Published: 22 July 2020

KEYWORDS:

Building structures, structural safety, risk management, construction projects, structural engineer

\begin{abstract}
A B S T R A C T
Many of the structural defects in the past have happened during the project development process. While a structural engineer must build a safe, economic and functional structure, the durability of the partially constructed structure cannot be ignored at various construction levels. During the building, structural health is a major problem for the industry of construction. Collapses of temporary structures or unfinished permanent structures pose a hazard to safety. Predictive risk analysis methods have been applied over the past decade to evaluate the efficiency of the current existing structural building framework. Identification of risks is aimed at recognizing possible risks that can result in accidents. It describes the types of hazards and random parameters connected with the individual risks and subsequent incidents. The quantifying risk values identified with building structures built according to uniform rules are widely distributed. This study provided importance to a conversation about risk and safety in building structures under construction, to build buildings without damage and destroying, also steps of safety in building structures. The outcome of the project depends on the specifics of the prescription. Building structure safety may lead to big problems if subjected to those loads such as earthquakes and storms. A lot of structural problems happen during construction. Most failures were related to a malfunction in the formwork. This study describes how building systems can carry risks to buildings, as well as resisting the impact of loads that could cause trouble.
\end{abstract}

\section{INTRODUCTION}

Building sites are generally regarded as one of the hardest places to work. Safety during construction is considered to be poor. A significant proportion of the total number of structural faults already exists during a structure's construction phase (Terwel et al., 2014). The paper explains the overall context and motivates how the safety and risk of building structures can be measured. Besides, the building structures have to meet the safety and serviceability specifications. Required evaluations can be categorized into three interconnected components: architectural quality, properties of material and structural behaviour. (Hu et al., 2020).

Building sustainability evaluation goes far further than evaluating building elements or services only (Nag, 2019). Scoring and qualification have increased concern about sustainability and efficient building under the basic framework of building sustainability (Buitrago et al., 2020). Supplements of the legislation by adequately founded and hypothetically tested requirements to govern the safety of the loads and behaviour for structures and buildings through construction and above design (Travush et al., 2016).

The acceptable standard of risk to structures would also be affected by the structure's very nature and the function under which it is planned. Structural failures are unusual, and therefore the reaction of the public to the unexpected needed to be significant (Blockley, 1980). During construction, the failure of a structure is due to unnecessary loading and/or insufficient strength of the structure (Ayyub, 1983). Harm to structures relates primarily to cracks, foundation settlements, material deterioration and dislocations (D'Ayala \& Fodde, 2008).

\section{METHODOLOGY}

Making sure safety problems are prepared, coordinated, controlled, managed and checked is the key to ensuring safe working conditions. The goal of the study is to identify the correct form of product use that will provide within the building structures for the execution of project aims. Usage of the method of assessment was used for this study. The study included a critical review and a description of the literature project basis. 
Table 1. Some example of methodologies and the aims of relevant studies

\begin{tabular}{|l|l|}
\hline Author & Methodology and aims \\
\hline $\begin{array}{l}\text { Cheng et al. } \\
(2010)\end{array}$ & $\begin{array}{l}\text { The author used a frequency variable for } \\
\text { this issue to assess risks. }\end{array}$ \\
\hline $\begin{array}{l}\text { Ghousi et al. } \\
(\mathbf{2 0 1 8})\end{array}$ & $\begin{array}{l}\text { The author presents a new robust safety risk } \\
\text { assessment process with the addition of the } \\
\text { Hybrid Value Number (HVN) to the meas- } \\
\text { urement equation. }\end{array}$ \\
\hline $\begin{array}{l}\text { Sun et al. } \\
(\mathbf{2 0 0 9 )}\end{array}$ & $\begin{array}{l}\text { The author attempted to prioritize current } \\
\text { con-structural risks. Described five likeli- } \\
\text { hood levels, and five impact levels to evalu- } \\
\text { ate risks. }\end{array}$ \\
\hline $\begin{array}{l}\text { Al-Anbari et } \\
\text { al. (2015) }\end{array}$ & $\begin{array}{l}\text { The author conducted a study to illustrate } \\
\text { how much quality assurance affects perfor- } \\
\text { mance and the various techniques used to im- } \\
\text { plement quality control. }\end{array}$ \\
\hline $\begin{array}{l}\text { Olmati et al. } \\
(\mathbf{2 0 1 7})\end{array}$ & $\begin{array}{l}\text { The author uses a single structural model. } \\
\text { The design could be accomplished by adding } \\
\text { specific safety factors to the load and struc- } \\
\text { tural resistance. }\end{array}$ \\
\hline
\end{tabular}

Reports from the articles, scientific journals and related books have been submitted through critical authors. Research study design guides have helped the researchers explain the problems, questions, and offer useful insights into how to establish effective research.

\section{OBJECTIVE OF STUDY}

Until completion, every building has to pass through many stages; design, planning and scheduling, construction system selection, and construction and manufacturing. As long as human beings are flawed, mistakes in nature cannot be avoided entirely, and mistakes in construction are possible. Should some of the subsystems of the building collapse during construction, e.g. a floor slabs, floor columns, etc., the building may be believed to have fallen. The risk of a building collapse during construction can be calculated by the structural system's probability of collapse (or reliability). To measure the "safety of construction" or the durability of an incomplete structure, measurement of both loads and resistance of the incomplete structure is needed again. Safety in a building structure is very critical because the industry is vulnerable to risk and can be harmful.

Additionally, the study aim is to be defined factors influencing the hazard and safety of building structures. The foundation of this work is, therefore, con-structure programs, as it relates to the design of the building. Safety and the removal of risk on the building is one of the essential goals of any building construction. To ensure all safety considerations were considered before starting. As a result, also, it was important to understand what particular safety criteria in the building structures would be implemented and how.

\section{BUILDING STRUCTURAL SYSTEMS}

A building's structural system is built to handle the longitudinal motion forces, mostly lateral loads produced by wind and seismic activity. The structural system consists of only members configured to hold the loads, most other members not involved in the carriage of loads are related to as non-structural members (Rana \& Rana, 2014). This was thought that structural members bear mainly loads of gravity. However, building capacity is minimized by advances in a system of structures, maximum capacity materials and slenderness is raised, which includes consideration of horizontal forces like wind and seismic activity in particular. Such structural systems apply to all building types, metal constructions, reinforced concrete structures and combined structures(Gunel \& Ilgin, 2007):

- Stiff frame structures,

- Walled frame bracing and shear structures,

- Outrigger structures,

- Pipe framed structures,

- Pipe braced structures,

- Pipe bundled structures.

The structural system is likely as a response to the attempt to obtain a structural system which allows for a big improvement to multiple volumetric design limitations, and also the capacity to make simple and efficient modifications of the building's structure during the time covered (Lozano et al. 2019). Fig. 1 includes the categorization of the structural building system (Abdul-Kadir et al., 2005).

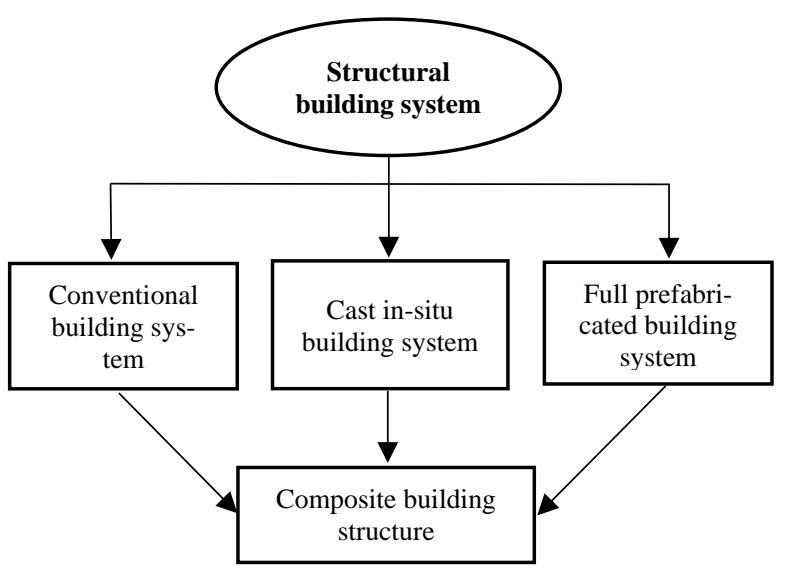

Fig. 1. Classification of structural building system

\section{BUILDING STRUCTURAL PERFOR- MANCE}

Performance is commonly defined as behaviour related to a given service. It is an indicator a building is performing its functions too. The performance can, in theory, be connected to strength, stability, structural safety, etc. Structural performance is also a function of time, which is why the performance is usually correlated with words like 'overtime' 
or 'with time'. The definition of durability is established as time is considered in the assessment of structural performance. Durability is a structural product that expresses the capability to sustain the performance required. Over time the performance can be modified at different levels: the materials, system of structures, component of structures $(\mathrm{Li}$, 1997). To perform an active performance assessment, a detailed and systematic methodology is necessary, which includes all buildings showing requirements.

Performance is assessed given the collection for parameters which decide for which the integration of structures is crucial as well as the degree of interaction can achieve the desired output when identified. Building reliability is improved by the logical decision of building materials and also the incorporation of systemic, mechanical function, cover and inner structures into the process of the building transition. Incorporation of structural building focus may not be on product and element assembly, yet even in terms of environmental conditions gained within the assembly as well as how to react the residents for those environmental states thus created (Mahbub et al., 2010).

\section{EVALUATION OF SAFETY}

\subsection{Identification of building structural safety}

The core idea of structural preservation is to protect the structures from risks created by man and the environment. The safety of a structure is commonly known as reserve faults resist. The structural safety assessment also is based on the fact that a degree of safety is required to cover complexities in construction manufacturing, materials, and analytical techniques and construction methods. Structural safety is heavily reliant on knowledge-based perception and decision, so safety decisions cannot be made purely by empirical probability and dynamics models (Ünay, 2007).

The safety evaluation during construction will be based on the fact that stability and reliability are important for the entire protection system, the key safety requirement is the stability of the protection mechanism of the works of the defence as a whole. The considerable reference criteria for the safety standard in vector control was the real degree of hazard covered by control systems (Suda et al., 2009). One of the conventional measures to ensure structural health is just to maintain the pressure of model forces below some amount that is named acceptable pressure (Paik, 2019).

The new structure design is a creation of concepts based on several concepts, eventually defining how the structures will materialize. Material performance is consistent in most situations, and the intended structural safety can be obtained. In practice, designing "on the safe side" is popular, rather than going into depth with the material modelling and structural behaviour. The exact reality of the construction, the structural behaviour, the exact materials and the age and degradation of the structure need to be taken into account
(Høj \& Söderqvist, 2009). The collapse of the structural buildings is typically caused by structural strength degradation. Maintenance is expected during the use of the buildings due to the degradation. Otherwise, the building's design service life cannot be satisfied, which presents a risk to public life (Li, 1997).

\subsection{Factors affecting building structural safety}

The safety factors can be identified as the proportion of the building structure's strength ability to the applied load effects. So, a well-performed structural analysis is required to establish the safety level rationally (Ünay, 2007). The factors that found affect safety include:

-Lack of proper regard by designers for the viability of erection,

- Insufficient site investigation,

- Impact or explosion,

- Formwork, a mistake in bracing and/or erection,

-Design error (Ayyub, 1983).

-Economical

- Procedural (Sawacha et al., 1999).

-Material properties,

-Load types,

- Speed loading,

- Temperature,

-Fabrication-Related Initial defects (Paik, 2019).

\section{EVALUATION OF RISK}

\subsection{Assessment of risks in building structures}

Risk assessment is aimed at identifying possible risks which may cause accidents. It describes the risk categories and statistical factors correlated with separate risks and resulting crashes (Paik, 2019). Risk is a term which has several aspects. To the benefit of the project, in the construction field, the probability of a defined cause and mixture of variables occurring throughout the construction phase can be. There are three key stages to a systemic risk management approach in the construction sector: a) hazard assessment, b) hazard identification, with evaluation, c) hazard Resolution. (Wang et al., 2004).

Risk management is an organized and ordered method of regularly defining, assessing and reacting to risks during a project's life-cycle to achieve the highest risk level reduction, prevention and check (Andi \& Adi, 2006).

The construction risks can be considered for management purposes as:

- Innate hazards: These become exceedingly difficult to monitor or manage since they are relative to both the construction project and integrated personnel structures such (environmental disasters that inflict behaviour on buildings). 
- Inherent hazard worsening: These involve a disgusting personnel error, happening within project building assets and controlled personnel systems such (collapse of a model, the collapse of building systems, etc.) (Almeida et al., 2010).

\subsection{Risk categories}

There are three risk categories opened up in engineering structures(Paik, 2019):

- Staff risks,

- Money risks,

- Habitat risks.

\subsection{Failure of building structures under construction}

The buildings' risk of damage structure through construction is necessary. Construct is among the most crucial stages of buildings lifespan it is because of the hazard of destruction and also the probability of construct forces will be under evaluation (Buitrago et al., 2020). Structural failures may range from walls that fall due to distant excavations weakening their foundations to buildings while working on a modification, due to weakening and/or overloading of the structure. During the destruction, structures may also fall suddenly, unless action is taken to avoid instability. Structures during construction can even fall, ex steel frames not properly braced, or overly loaded formwork (Williams, 2006).

Table 2. Classified list of concrete building failures under construction

\begin{tabular}{|l|c|}
\hline Cause of failure & Per cent of total failure \\
\hline Failure of formwork & $54 \%$ \\
\hline Fire & $18 \%$ \\
\hline Faulty material & $8 \%$ \\
\hline Premature shore exclusion & $8 \%$ \\
\hline Overloading & $4 \%$ \\
\hline Soil failure & $4 \%$ \\
\hline Others & $4 \%$ \\
\hline Total & $100 \%$ \\
\hline
\end{tabular}

The principal cause of damage to the building is the frequent earthquakes that have impacted the structure during its lifetime (Ercan, 2018). Many building structural failures under construction happen during or merely after pouring concrete, and so many of the failures have been caused by formwork failure. Table 2 classified list of concrete building failures under construction (Ayyub, 1983).

\section{CONCLUSION}

The safety and risk analysis of the structural building under construction theory is established and incorporated to a specific degree, we have focused on a variety of natural factors concerning an engineering structure and impacting its safety. Safety structural buildings may become a matter of greatest importance if they are subjected to exceptional behaviour such as storms or earthquakes, but particularly if their maintenance is deficient during use. Failure to maintain may also cause the roof or the attic slab to collapse or changing of the load path in incomplete structures. Researchers will concentrate on identifying the factors that affect safety risks most. More functional work may depend on the safety program's details. Through interviewing in building structures, this paper established important risks and safeties, plus their protection measures.

From the study review discussed in this report, it is seen that during the project construction phase, the amount of building structural faults in the past occurred. Many systemic defects occur during construction or immediately after concrete has been poured. Many of those failures were due to a formwork malfunction. Such failures are largely due to human error, poor optimization of construction procedures and techniques. Also, high variability in construction loads and the response of building structures. The key explanation for the large percentage of false job failures is design flaws and the inability of staff and engineers to follow safety measures. The safety factors can be identified as the ratio of the building structures 'strength capability to the applied load impacts.

\section{CONFLICT OF INTEREST STATEMENT}

The author declare that there is no conflict of interest.

\section{REFERENCES}

[1] Abdul Kadir, M. R., Lee, W. P., Jaafar, M. S., Sapuan, S. M., \& Ali, A. A. A. (2005). Performance comparison between the structural elements of building systems in Malaysia. American Journal of Applied Sciences, 2(5), 1014-1024. https://doi.org/10.3844/ajassp.2005.1014.1024

[2] Al-Anbari, S., Khalina, A., Alnuaimi, A., Normariah, A., \& Yahya, A. (2015). Risk assessment of safety and health (RASH) for building construction. Process Safety and Environmental Protection, 94, 149-158. https://doi.org/10.1016/j.psep.2015.01.009

[3] Almeida, N., Sousa, V., Alves Dias, L., \& Branco, F. (2010). A framework for combining risk-management and performance-based building approaches. Building Research \& Information, 38(2), 157-174. https://doi.org/10.1080/09613210903516719

[4] Andi, S. A. N. T. I., \& Adi, D. (2006). Identifying and managing important risks in building and infrastructure projects: the contractors' perspective. In Proc. International civil engineering conference towards sustainable civil engineering practice, Sarabia, 25-26. 
[5] Ayyub, B. M. D. S. (1983). Structural safety analysis of reinforced concrete buildings during construction [Doctoral dissertation, Georgia Institute of Technology]. Georgia Institute of Technology.

[6] Blockley, D. I. (1980). The nature of structural design and safety, (1st ed.). Chichester: Ellis Horwood.

[7] Buitrago, M., Sagaseta, J., \& Adam, J. M. (2020). Avoiding failures during building construction using structural fuses as load limiters on temporary shoring structures. Engineering Structures, 204, 109-121. https://doi.org/10.1016/j.engstruct.2019.109906

[8] Cheng, C. W., Leu, S. S., Lin, C. C., \& Fan, C. (2010). Characteristic analysis of occupational accidents at small construction enterprises. Safety Science, 48(6), 698-707. https://doi.org/10.1016/j.ssci.2010.02.001

[9] D'Ayala, D., \& Fodde, E. (2008). Structural Analysis of Historic Construction: Preserving Safety and Significance. Proceedings of the VI International Conference on Structural Analysis of Historic Construction, ( $1^{\text {st }}$ ed.). SAHC08, 2008, Bath, United Kingdom. Taylor and Francis.

[10] Ercan, E. (2018). Assessing the impact of retrofitting on structural safety in historical buildings via ambient vibration tests. Construction and Building Materials, 164, 337-349.

https://doi.org.ezproxy.neu.edu.tr/10.1016/j.conbuild mat.2017.12.154

[11] Ghousi, R., Khanzadi, M., \& Mohammadi Atashgah, K. (2018). A flexible method of building construction safety risk assessment and investigating financial aspects of the safety program. International Journal of Optimization in Civil Engineering, 8(3), 433-452.

[12] Gunel, M. H., \& Ilgin, H. E. (2007). A proposal for the classification of structural systems of tall buildings. Building and Environment, 42(7), 2667-2675. https://doi-org.ezproxy.neu.edu.tr/10.1016/j.buildenv.2006.07.007

[13] Нøj, N. P., \& Söderqvist, M. K. (2009). Performance and safety of existing structures: Introduction. Structural Engineering International, 19(2), 165-165. https://doi.org/10.2749/101686609788220204

[14] Hu, J., Chen, W., Qu, Y., \& Yang, D. (2020). Safety and serviceability of membrane buildings: A critical review on architectural, material and structural performance. Engineering Structures, 210, 110292. https://doi.org/10.1016/j.engstruct.2020.1102925

[15] Li, C. Q. (1997). Deterioration of concrete building structures. Building Research \& Information, 25(4), 196-201. https://doi.org/10.1080/096132197370318

[16] Lozano, D., Martín, Á., Serrano, M. A., \& López-Colina, C. (2019). Design of a flexible structural system for building customization. Advances in Civil Engineering, 38(4), 202-211. https://doi.org/10.1155/2019/2103830
[17] Mahbub, A. S., Kua, H. W., \& Lee, S. E. (2010). A total building performance approach to evaluating building acoustics performance. Architectural Science Review, 53(2), 213-223. https://doi.org/10.3763/asre.2009.0032

[18] Nag, P. K., Nag, P. K. (2019). Office Buildings. (1st ed.). Springer Singapore. https://doi.org/10.1007/978-981-13-2577-9

[19] Olmati, P., Vamvatsikos, D., \& Stewart, M. G. (2017). Safety factor for structural elements subjected to impulsive blast loads. International Journal of Impact Engineering, 106, 249-258. https://doi.org/10.1016/j.ijimpeng.2017.04.009

[20] Paik, J. K. (2019). Advanced Structural Safety Studies: With Extreme Conditions and Accidents. ( $1^{\text {st }}$ ed.). Springer, pp. 57-76, (Vol. 37). https://doi.org/10.1007/978-981-13-8245-1

[21] Rana, E. N., \& Rana, S. (2014). Structural forms systems for tall building structures. SSRG International Journal of Civil Engineering, 1(4), 33 -36.

[22] Sawacha, E., Naoum, S., \& Fong, D. (1999). Factors affecting safety performance on construction sites. International Journal of Project Management, 17(5), 309-315.

[23] Suda, J., Strauss, A., Rudolf-Miklau, F., \& Hübl, J. (2009). Safety assessment of barrier structures. Structure and Infrastructure Engineering, 5(4), 311-324. https://doi.org/10.1080/15732470701189498

[24] Sun, Y., Fang, D., Wang, S., Dai, M., \& Lv, X. (2009). Safety Risk Identification and Assessment for Beijing Olympic Venues Construction. Journal of Management in Engineering, 25(2), 98-100.

[25] Terwel, K., Booth, W., \& Nelisse, M. (2014). Structural unsafety revealed by failure databases. Proceedings of the Institution of Civil Engineers-Forensic Engineering, 167(1), 16-26.

[26] Travush, V., Emelianov, S., Kolchunov, V., \& Bulgakov, A. (2016). Mechanical safety and survivability of buildings and building structures under different loading types and impacts. Procedia Engineering, 164, 416-424.

https://doi-org.ezproxy.neu.edu.tr/10.1016/j.proeng.2016.11.639

[27] Ünay, A. İ. (2007). Evaluation of the structural safety of historical masonry buildings. Architectural Science Review, 50(1), 26-30. https://doi.org/10.3763/asre.2007.5004

[28] Wang, S. Q., Dulaimi, M. F., \& Aguria, M. Y. (2004). Risk management framework for construction projects in developing countries. Construction Management and Economics, 22(3), 237-252. https://doi.org/10.1080/0144619032000124689

[29] Williams, S. (2006). Health and Safety in Construction. $\left(3^{\text {rd }}\right.$ ed). Health and Safety Executive (HSE). 